\title{
Bleeding from gastroduodenal metastases as the first manifestation of lung adenocarcinoma
}
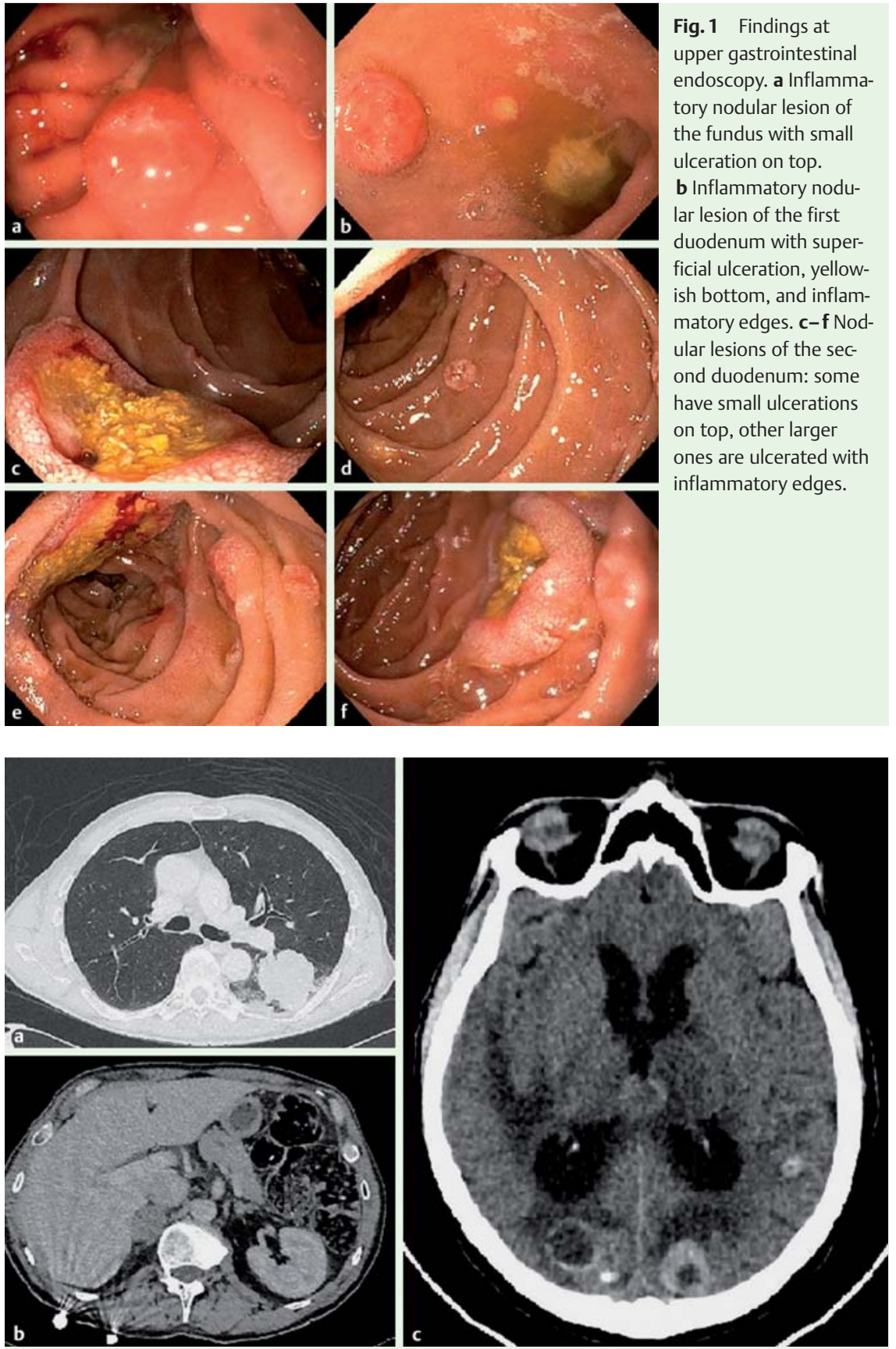

Fig. 3 Body computed tomography scan. a Thorax: hyperdense nodule with spiculated margins and contact with pleura. b Abdomen (injected, portal phase): hypodense nodules in the right adrenal gland and in the body of the pancreas. $\mathbf{c}$ Brain (injected): occipital on both sides, left temporal and mesencephalic nodules with target patterns.

Gastrointestinal metastases from lung cancer are rarely symptomatic [1]. They can cause gastrointestinal bleeding [2,3], acute abdominal pain [4], and perforation [5]. We describe herein a case of acute anemia secondary to gastroduodenal

Fig. 1 Findings at upper gastrointestinal endoscopy. a Inflammatory nodular lesion of the fundus with small ulceration on top. b Inflammatory nodular lesion of the first duodenum with superficial ulceration, yellowish bottom, and inflammatory edges. c- $\mathbf{f}$ Nodular lesions of the second duodenum: some have small ulcerations on top, other larger ones are ulcerated with inflammatory edges.
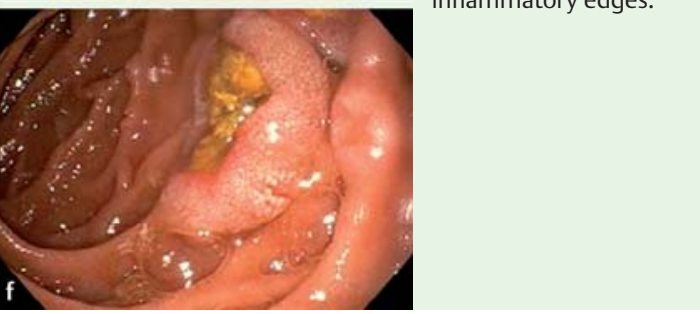
Endoscopy_UCTN_Code_CCL_1AB_2AD_3AB

\section{Competing interests: None}

\section{Charlotte Bouzbib' ${ }^{1}$ Ulriikka Chaput' Irène Jarrin ${ }^{2}$, Anne Lavergne-Slove ${ }^{3}$, Philippe Marteau ${ }^{1,4}$, Xavier Dray ${ }^{1,4}$}

${ }^{1}$ Department of Gastroenterology and Hepatology, APHP Lariboisière Hospital, Paris, France

2 Department of Internal Medicine, APHP Lariboisière Hospital, Paris, France

${ }^{3}$ Department of Pathology and Cytology, APHP Lariboisière Hospital, Paris, France

${ }^{4}$ Paris 7 University, Paris, France

\section{References}

1 Lee PC, Lo C, Lin MT et al. Role of surgical intervention in managing gastrointestinal metastases from lung cancer. World J Gastroenterol 2011; 17: 4314-4320

2 Kostakou C, Khaldi L, Flossos A et al. Melena: a rare complication of duodenal metastases from primary carcinoma of the lung. World J Gastroenterol 2007; 13: 1282 - 1285

3 Raijman I. Duodenal metastases from lung cancer. Endoscopy 1994; 26: 752 - 753

4 Börsch G, Schmidt G, Sperling J et al. Gastroduodenal metastases - an unusual initial manifestation of bronchogenic carcinoma. Endoscopy 1984; 16: 118-121

5 Garwood RA, Sawyer MD, Ledesma EJ et al. A case and review of bowel perforation secondary to metastatic lung cancer. Am Surg 2005; 71: 110-116

\section{Bibliography}

Dol http://dx.doi.org/ 10.1055/s-0034-1377540

Endoscopy 2014; 46: E474-E475

(c) Georg Thieme Verlag KG

Stuttgart · New York

ISSN 0013-726X

\section{Corresponding author}

\section{Ulriikka Chaput, MD}

Department of Gastroenterology and Hepatology APHP Lariboisière Hospital

2, rue Ambroise Paré

75010 Paris

France

Fax: +33-1-49952577

ulriikka.chaput@lrb.aphp.fr 